\title{
TECNOLOGIAS DE AEROGERADORES APLICADOS EM SISTEMAS DE GERAÇÃO DE ENERGIA EOLIOELÉTRICA
}

Diego Meireles Lopes

Bacharelando em Engenharia de Produção, Universidade Santa Úrsula/USU, rio de Janeiro - RJ diego.lopes@souusu.com.br

Alessandra de S. de Macedo Lopes Especialista em Gestão de Energia e Eficiência Energética e Mestranda em Engenharia AmbientalUniversidade Federal do Rio de Janeiro/UFRJ, Rio de Janeiro-RJ alessandra.macedo@poli.ufrj.br

Luiz Claudio Rego Campos Engenheiro Eletricista, Centro Universitário Augusto Motta/UNISUAM, Rio de Janeiro - RJ luiz.rego@marcampos.com.br

\section{RESUMO}

O presente artigo apresenta um estudo teórico de engenharia na área de geração de energia eolioelétrica voltado para apresentação das tecnologias de aerogeradores. O principal objetivo foi realizar uma breve revisão bibliográfica para avaliar o desenvolvimento das tecnologias de aerogeradores para produção de energia eólica no Brasil. A metodologia empregada foi uma pesquisa a partir da revisão bibliográfica de artigos acadêmico-científicos e documentos elaborados pelo corpo técnico de órgãos e agências governamentais, e demais publicações técnicas a respeito da energia eolioelétrica no Brasil. O resultado do trabalho foi apresentação das tecnologias de aerogeradores, com base nas boas práticas de engenharia, em atendimento as normas técnicas pertinentes e legislação vigente.

Palavra-chave: Aerogeradores; Energia eólica; Força dos Ventos.

\section{AEROGENERATOR TECHNOLOGIES APPLIED IN WIND ENERGY GENERATION SYSTEMS}

\begin{abstract}
This article presents a theoretical engineering study in the field of wind power generation aimed at presenting wind turbine technologies. The main objective was to carry out a brief literature review to assess the development of wind turbine technologies for wind energy production in Brazil. The methodology used was a research based on a bibliographic review of academic-scientific articles and documents prepared by the technical staff of government agencies and agencies, and other technical publications on wind power in Brazil. The result of the work was the presentation of wind turbine technologies, based on good engineering practices, in compliance with the relevant technical standards and current legislation.
\end{abstract}

Keywords: AEROGENERATOR; Wind Energy; Wind Power 
Segundos dados da Empresa de Pesquisa Energética-EPE (2020), o Brasil alcançou, em 2019, o patamar de 15.378 MW em disponibilidade de potência instalada em parques eólicos distribuídos pelo país, representando um acréscimo de 6,9\% em relação ao ano anterior.

Em 2011, a energia eólica passou a ser considerada a segunda fonte de energia renovável mais competitiva no Brasil. E, no ano de 2016 haviam instalados 400 parques eólicos pelo país, atingindo a marca de $10 \mathrm{GW}$ de produção de energia elétrica (ABEEÓLICA, 2021).

Ainda, segundo o Global Wind Energy Council, o Brasil, que em 2012 ocupava a 15a posição no ranking mundial de países produtores de energia eólica, em 2020 fechou o ano na 7ạ posição do referido ranking. Além disso, o Brasil também lidera o ranking de novas instalações eólicas anuais na América Latina, conforme pode ser observado no gráfico 1, tendo acrescido 2,3 GW de capacidade instalada em 2020 (GWEC, 2021).

Gráfico 1 - Instalações eólicas anuais na América Latina em 2020.

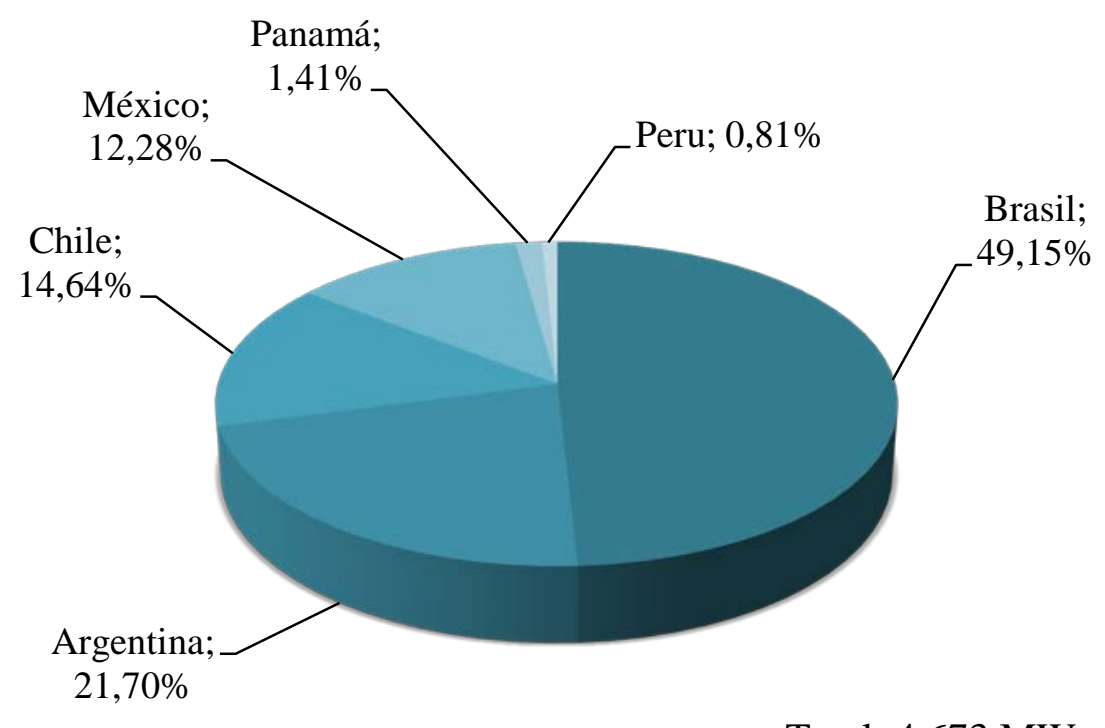

Total: 4,673 MW

Fonte: GWEC, 2021.

Em 2021, a capacidade instalada em parques eólicos distribuídos pelo Brasil atingiu o patamar de $18.459 \mathrm{MW}$, assim, representando a segunda fonte de geração de energia elétrica no País, perdendo somente para a energia elétrica gerada pelas usinas hidrelétricas. $E$, as projeções para o ano de 2025 confirmam a manutenção deste patamar, com um acréscimo estimado de 1,7\% em comparação ao ano a 2021 (ONS, 2021). 
A Empresa de Pesquisa Energética - EPE (2018) ressalta em seu relatório Desafios da Transmissão no Longo Prazo que com a perspectiva de crescimento da geração de energia elétrica através de fontes renováveis (especialmente a eólica e a fotovoltaica), para os próximos anos será necessária a ampliação do sistema de transmissão de energia elétrica.

Isto posto, com a ampliação dos investimentos em novos projetos de geração energia eolioelétrica no país e no mundo, bem como, o avanço no desenvolvimento tecnológico na construção de aerogeradores de grande porte nas últimas décadas, em especial o gerador de indução, gerador síncrono e geradores a imãs permanentes, conforme evidenciado na Figura 1.

Figura 1 - Desenvolvimento dos aerogeradores em função do diâmetro do rotor e potência

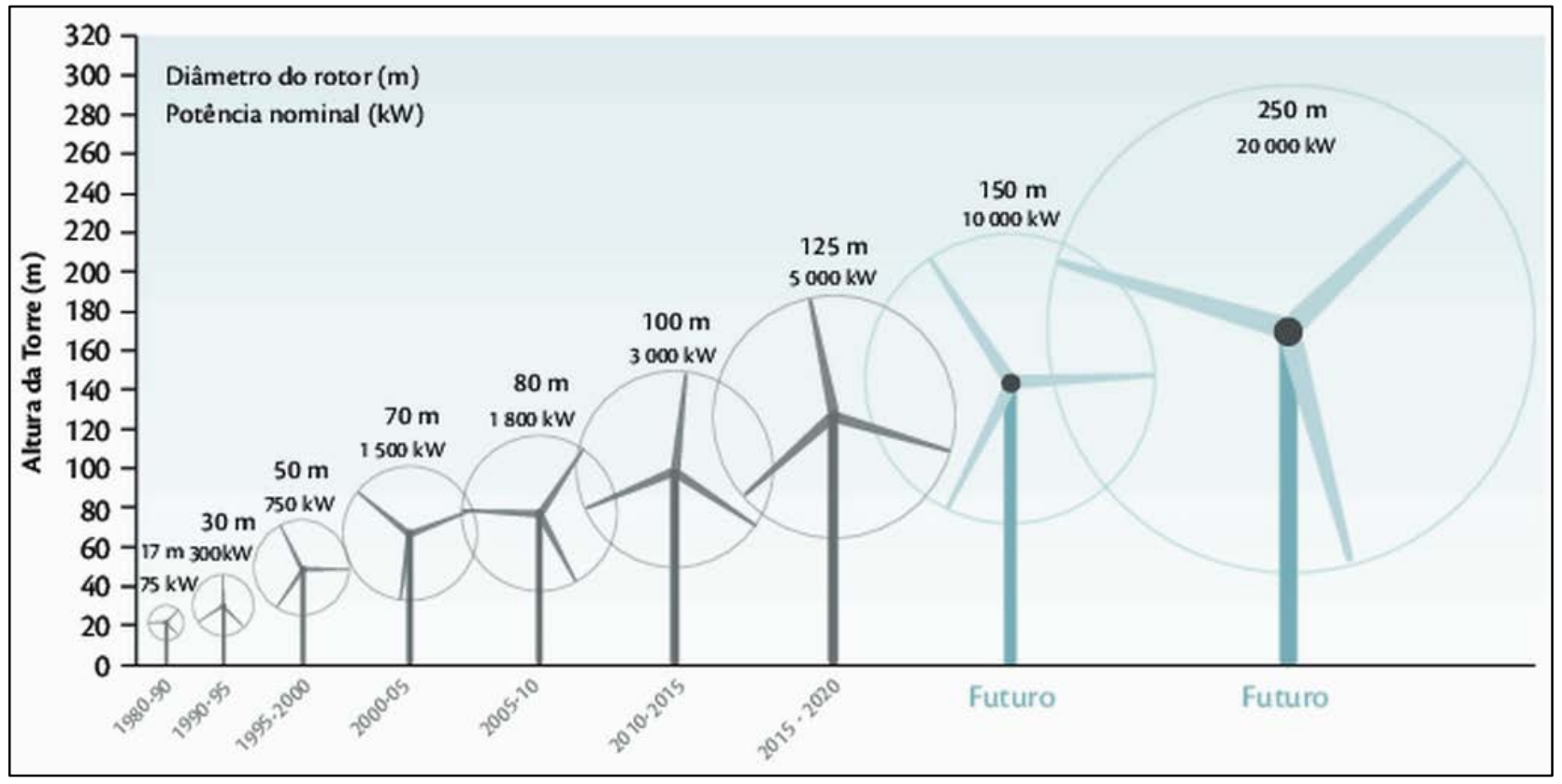

Fonte: (adaptado de IEA, 2013)

Os sistemas de geração de energia eólica podem ser classificados em sistemas que operam a velocidade constante e sistemas que operam a velocidade variável dependentes da tecnologia de conexão do gerador à carga ou à rede elétrica.

Assim, o presente artigo vem apresentar uma breve revisão teórica sobre o tema de tecnologias de aerogeradores aplicados em sistemas de geração de energia eolioelétrica para aplicação em parque eólicos onshore e offshore.

Ainda, no presente trabalho encontra-se informações técnicas sobre as tecnologias de rotores eólicos, geradores elétricos, entre outros, que compõem os mais modernos aerogeradores disponíveis no mercado nacional e internacional. 


\section{METODOLOGIA}

A metodologia empregada no presente artigo retrata uma breve pesquisa a partir da revisão bibliográfica de artigos acadêmico-científicos e documentos elaborados pelo corpo técnico da Empresa de Pesquisa Energética (EPE), do Operador Nacional do Sistema (ONS) e da Agência Nacional de Energia Elétrica (ANEEL), e demais publicações técnicas a respeito da energia eolioelétrica no Brasil.

\section{REVISÃO BIBLIOGRÁFICA}

A energia eólica pode ser aproveitada a partir da conversão da energia cinética do vento em energia mecânica de rotação para geração de energia elétrica como é o caso dos aerogeradores instalados em parques geradores de energia eolioelétrica (Cavadas, 2018).

Segundo Burton (2001), o princípio de funcionamento de um aerogerador é a utilização das forças do vento incidindo sobre as pás que estão conectadas ao cubo ou rotor, assim, estas forças são parcialmente transmitidas para um eixo que está conectado a uma caixa de engrenagem multiplicadora de velocidade pode aumentar a rotação na proporção de 1:88 no eixo conectado à saída da caixa multiplicadora, este movimentará elementos geradores de campo magnético no gerador, que por indução produzirá energia elétrica, conforme mostrado na figura 2:

Figura 2 - Sistema de aerogerador horizontal para geração de energia eólicoelétrica.

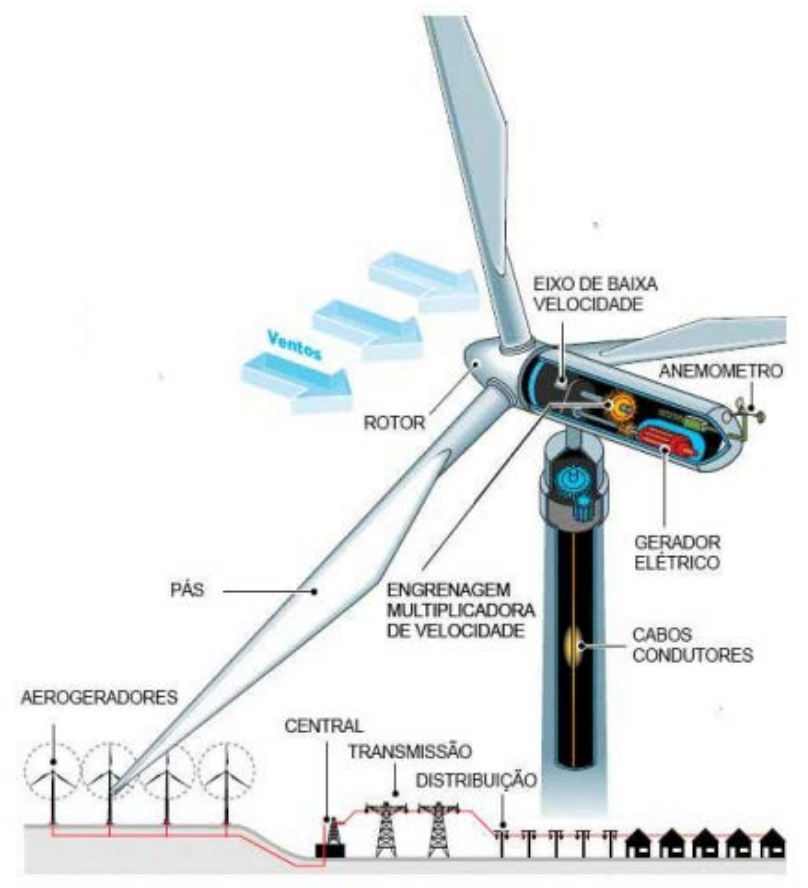

Fonte: (Cavadas, 2018) 


\section{1 - Tecnologia dos Aerogeradores}

Aerogeradores são equipamentos de conversão de energia, conforme apresentado na figura 3, onde parte da energia cinética dos ventos é convertida em energia mecânica, e esta, por sua vez, é transmitida ao rotor de um gerador que produz eletricidade.

Segundo Pinto (2018), pode-se classificar um aerogerador com base na direção de seu eixo: horizontal (horizontal axis wind turbine, HAWT) ou vertical (vertical axis wind turbine, VAWT).

Os aerogeradores de eixo vertical são menos vantajosos que os aerogeradores de eixo horizontal, isto deve-se principalmente a proximidade desses ao solo, onde a qualidade dos ventos, em especial sua velocidade, é pior.

Figura 3 - Princípio de conversão da energia cinética do vento em energia elétrica.
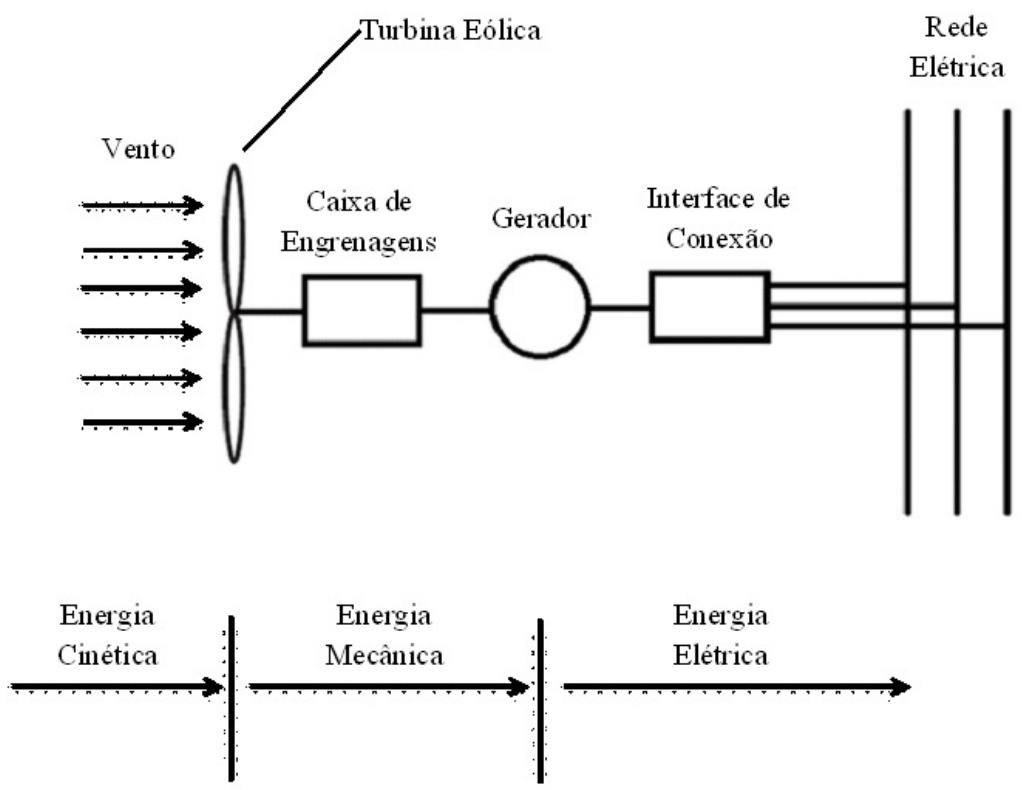

Fonte: (PINTO, 2018)

Os aerogeradores de eixo horizontal podem ser do tipo upwind (quando o vento incide na parte dianteira de varredura) ou downwind (quando o vento incide na parte traseira de varredura). Os aerogeradores de eixo horizontal do tipo upwind necessitam de um mecanismo automatizado para manter as pás orientadas ao vento, já nos do tipo downwind essa orientação se dá automaticamente com a força do próprio vento (PINTO, 2018).

A figura 4 apresenta um exemplo de parque eólico, localizado no município de São Francisco de Itabapoana, no estado do Rio de Janeiro, onde pode-se observar torres eólica com aerogeradores de eixo horizontal do tipo upwind. 
Figura 4 - Parque eólico de Gargaú com aerogeradores de eixo horizontal do tipo upwind.

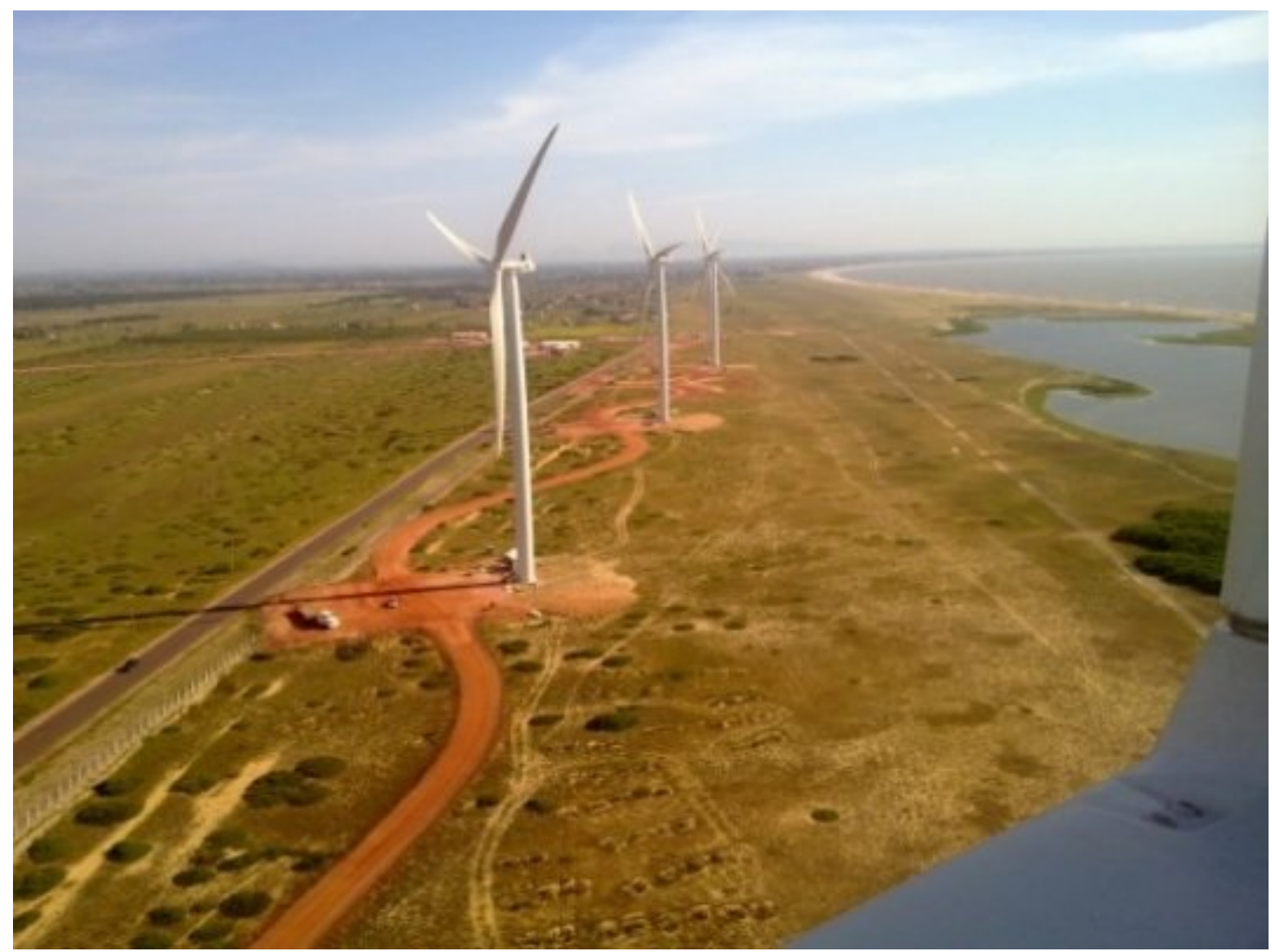

Fonte: (WEG, 2021)

Um aerogerador de eixo horizontal é composto pelas seguintes principais partes: torre, rotor e nacele. No rotor, responsável pela transformação da energia cinética dos ventos em energia mecânica, encontra-se o cubo onde as pás são fixadas.

A nacele, como pode ser observada na figura 5, é a caixa localizada no alto da torre, onde o conjunto gerador e demais engrenagens encontram-se.

Também é na nacele que está localizado o sistema de direção automatizado para ajuste do posicionamento da turbina na direção do vento. A torre sustenta a turbina e a nacele, além disso, é por ela que passam os cabos de conexão que transferem a energia elétrica gerada para um transformador step-up localizado, geralmente, na base.

Segundo Hansen (2012), um aerogerador pode ser de velocidade fixa (fixed-speed wind turbines) e de velocidade variável (variable-speed wind turbines).

Em aerogeradores de velocidade fixa, independente da velocidade do vento, a velocidade do rotor é determinada pela frequência da rede elétrica, pela relação de transmissão e pelo projeto do gerador. Estes são equipados com geradores de indução que estão diretamente ligados à rede com um soft-starter e um banco de capacitores para compensação reativa. 
Figura 5 - Componentes de um aerogerador.

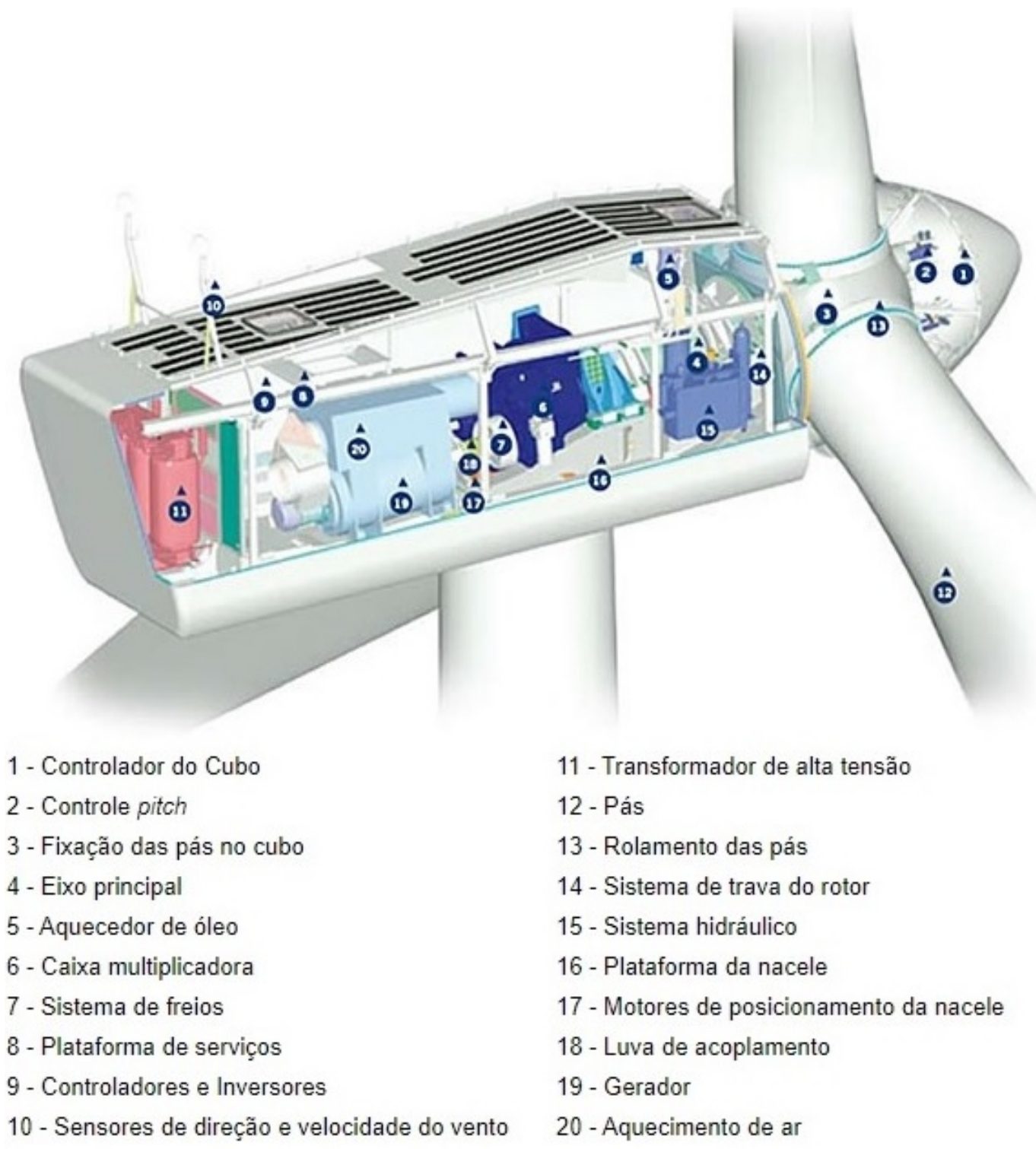

Fonte: (CRESESB, 2021)

Portanto, são projetados para alcançar a máxima eficiência em determinada velocidade de vento. Como vantagens, apresentam boa confiabilidade e baixo custo de manutenção, porém consomem energia reativa da rede elétrica, apresentam elevado estresse mecânico e, também, limitado controle da qualidade de energia.

Todas as flutuações na velocidade do vento são transmitidas como flutuações no torque mecânico e, por consequência, se tornam flutuações de energia na rede elétrica, o que pode resultar em uma grande flutuação de tensão com elevada perda. 
Com o passar do tempo, os aerogeradores de velocidade variável se tornaram o tipo mais comum em operação. Estes são projetados para atingir a maior eficiência aerodinâmica dentro de uma ampla escala de velocidades do vento.

É possível a adaptação da velocidade de rotação de acordo com a velocidade do vento. $\mathrm{O}$ torque do gerador é mantido constante, e as variações do vento são absorvidas por mudanças na velocidade do gerador.

Como vantagens tem-se uma melhor geração de energia elétrica, melhor qualidade da energia gerada e redução do estresse mecânico.

Por outro lado, as desvantagens esbarram nos custos elevados de manutenção e instalação (mais componentes) e perdas na eletrônica de potência (HANSEN, 2012).

Os quatro arranjos de aerogeradores HAWT em operação no sistema elétrico brasileiro atualmente são: Gerador de Indução, Gerador de Indução com controle no rotor, Double-Fed Asynchronous Inductive Generator (DFIG) e Full Converter (ONS, 2018).

\subsection{1 - Gerador de Indução}

Um gerador de indução gaiola de esquilo ( $\mathrm{SCIG}$ ) assíncrono, conforme mostrado na figura 6, é conectado diretamente a rede elétrica por meio de um transformador.

Como este tipo de gerador consome energia reativa, faz-se necessário o uso de um banco de capacitores para compensação. Já o soft-starter proporciona uma conexão à rede elétrica de forma "mais suave" (HANSEN, 2012).

Figura 6 - Gerador de Indução

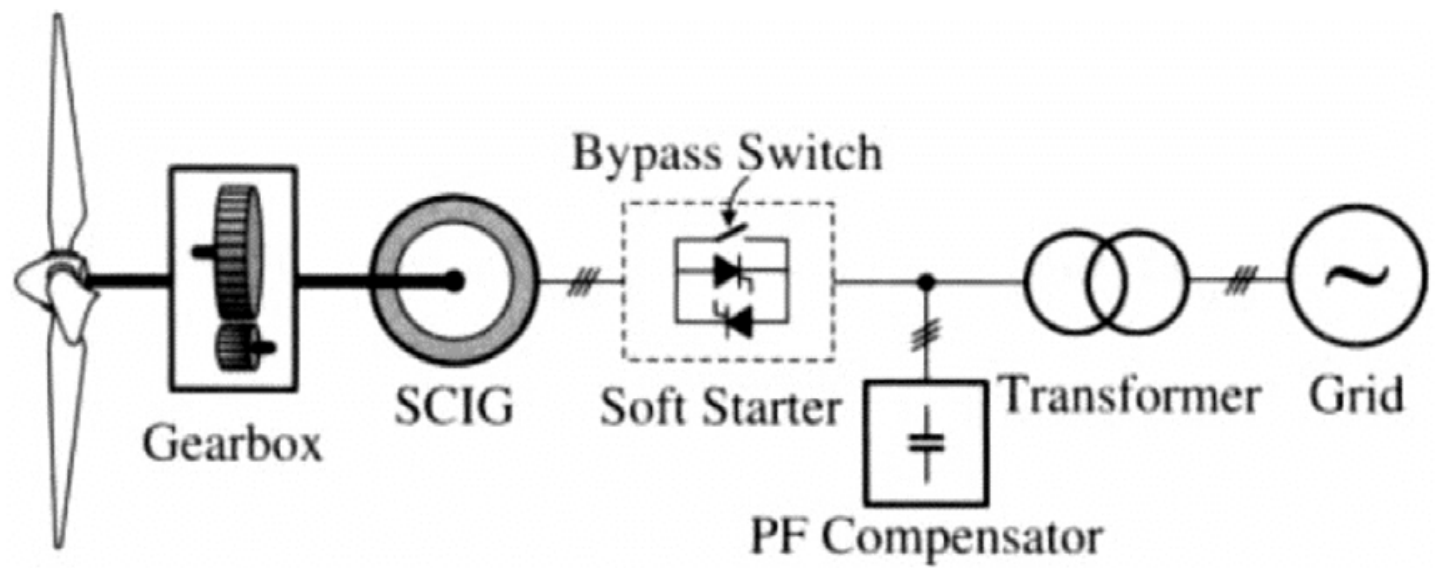

Fonte: (ONS, 2018) 


\subsection{2 - Gerador de Indução com controle no rotor}

Aerogerador composto por um gerador de indução com rotor enrolado (WRIG), conforme figura 7, possuindo uma resistência variável acoplada ao rotor que é controlada e alterada através de componentes eletrônicos.

Isto permite o controle do escorregamento (variável) e da saída de energia do gerador, resultando em flutuações menores no torque e na energia.

Com isto, representa uma maneira simples, confiável e econômica de obter redução de carga, em comparação a soluções mais complexas, como aerogeradores de velocidade variável.

O soft-starter é usado para reduzir a corrente de inrush no transformador, e o compensador reativo reduz significativamente (quase eliminando) a demanda de potência reativa pelo gerador.

Cabe ressaltar que, em comparação a configuração SCIG, a velocidade operacional é melhor.

Já a configuração WRIG, até certo ponto, reduz as cargas mecânicas e de flutuações de potência causadas por rajadas de vento, porém ainda requer uma compensação de energia reativa.

Como desvantagens, a faixa de velocidade é limitada (pois depende da resistência variável acoplada ao rotor), controle deficiente de potência ativa e reativa, e a potência do escorregamento é dissipada como perda (HANSEN, 2012).

Figura 7 - Gerador de Indução com controle no rotor

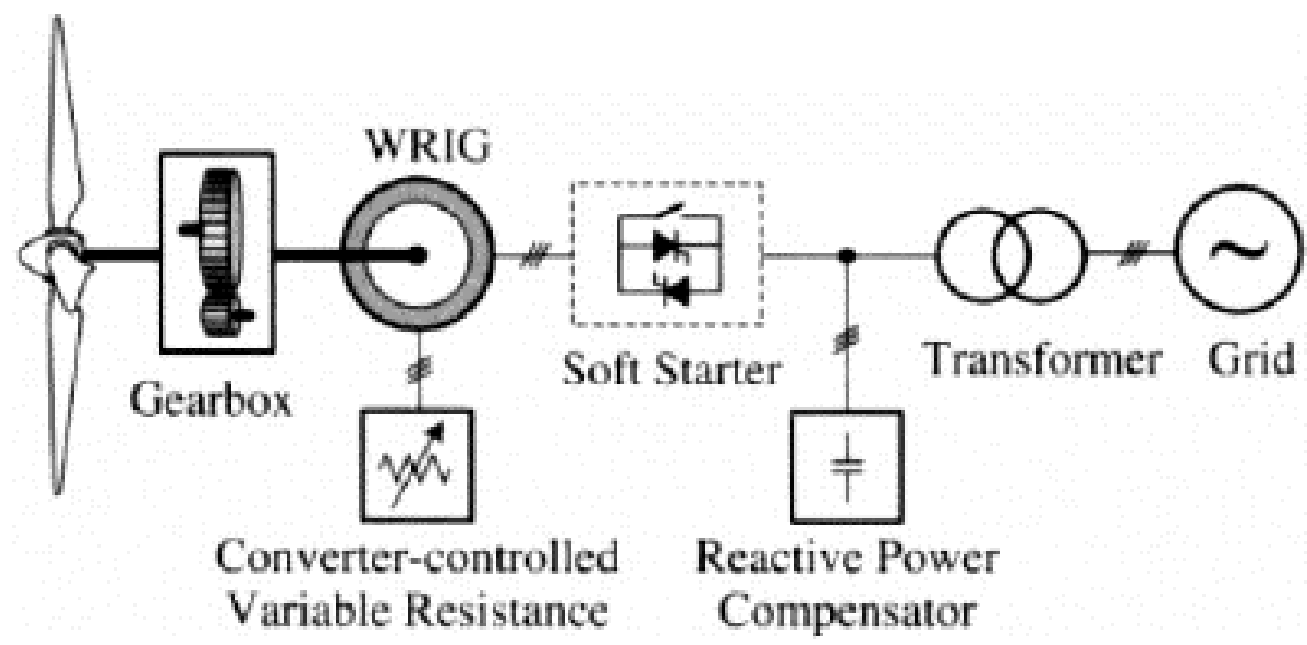

Fonte: (ONS, 2018) 


\subsection{3 - Double-Fed Asynchronous Inductive Generator (DFIG)}

O gerador de indução duplamente alimentado (DFIG), conforme figura 8, corresponde a um aerogerador de velocidade variável limitada (WRIG) com um conversor de frequência de escala parcial. Logo, não necessita de um soft-starter e nem de um compensador de potência reativa, visto que o conversor de frequência de escala parcial realiza ambas as funções.

Assim, possui uma faixa mais ampla de controle da velocidade dinâmica, bem como, também é atrativo economicamente em relação ao tamanho do conversor de frequência, mesmo sendo uma opção de custo mais elevado em relação às configurações SCIG e WRIG. As desvantagens desta configuração são a necessidade de uma proteção adicional no caso de falha na rede elétrica e o uso de anéis coletores para a ligação elétrica ao rotor (HANSEN, 2012).

Figura 8 - Double-Fed Asynchronous Inductive Generator (DFIG)

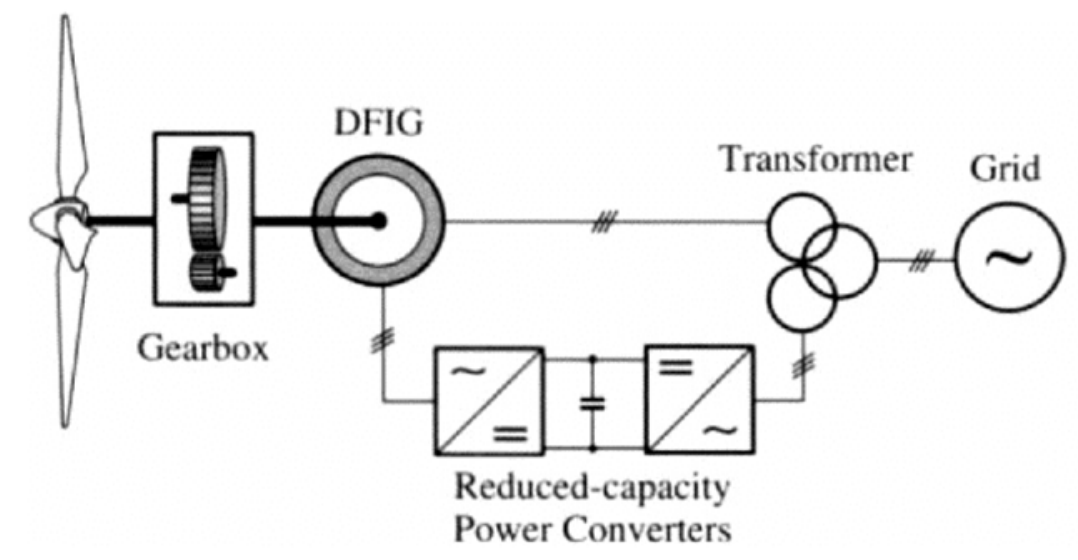

Fonte: (ONS, 2018)

\subsection{4 - Full Converter}

Esta configuração que corresponde ao aerogerador de velocidade variável completa com o gerador conectado à rede através de um conversor de frequência de grande capacidade, conforme apresentado na figura 9.

Este tipo de conversor de frequência permite uma conexão mais "suave" à rede elétrica e, também, um melhor controle das potências ativa e reativa. Além disto, apresenta perdas extras na conversão que são compensadas pelo desempenho.

O gerador pode ser excitado eletricamente, ou através de um ímã permanente, e nem sempre a caixa de engrenagens se faz necessária nesta configuração (HANSEN, 2012). 


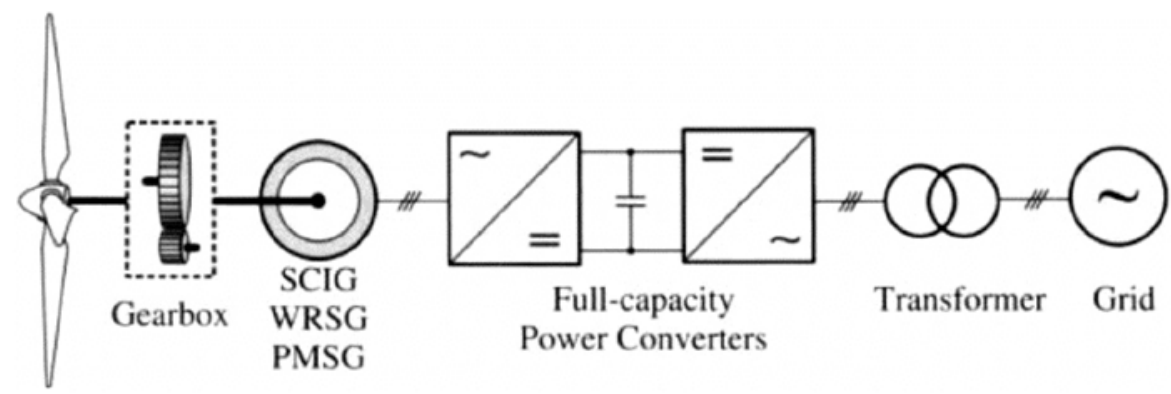

Fonte: (ONS, 2018)

\section{CONCLUSÃO}

Conclui-se então que, este trabalho é um estudo teórico com uma breve revisão sobre as tecnologias de aerogeradores aplicados em sistemas de geração de energia eolioelétrica, detalhando uma revisão da literatura sobre energia eólica, tecnologias de aerogeradores, assim, visando apresentar o seu estado da arte.

Portanto, com o desenvolvimento das tecnologias dos geradores eólicos a capacidade instalada tende a crescer cada vez mais no Brasil, mantendo o patamar como a segunda maior fonte de energia elétrica gerada no país.

Desta forma, recomenda-se a continuidade de novos estudos sobre o tema abordado, tendo em vista o desenvolvimento da geração de energia eólica na matriz energética brasileira e mundial.

Por derradeiro, no futuro próximo esta tecnologia de aerogeradores estará autorizado, sob a ótica do licenciamento ambiental, para instalações de parques eólicos offshore na costa brasileira.

\section{REFERÊNCIAS}

Agência Nacional de Energia Elétrica - Aneel. EOL - Mapa dos Empreendimentos de Geração Eólicas (Estágio da usina). Disponível em: https://bit.ly/3ISCdl4. Acesso em: 23 de março de 2021.

Associação Brasileira de Energia Eólica - ABEEólica. Quem somos? Disponível em: www.abeeolica.org.br/quem-somos/. Acesso em: 27 de janeiro de 2021.

BRASIL, Câmara dos Deputados. Lei no 10.848, de 15 de março de 2004. Disponível em: https://www2.camara.leg.br/legin/fed/lei/2004/lei-10848-15-marco-2004-531234normaatualizada-pl.html. Acesso em: 26 de março de 2021.

BRASIL, Presidência da República. Lei no 10.438, de 26 de abril de 2002. Disponível em: http://www.planalto.gov.br/ccivil_03/leis/2002/I10438.htm. Acesso em: 26 de março de 2021. 
CAVADAS, Leornado de Souza INTEGRAÇÃO DE DADOS DE SISTEMAS DE GERAÇÃO DE ENERGIA RENOVÁVEIS: IMPLEMENTAÇÃO NO POLO DE INOVAÇÃO CAMPOS DOS GOYTACAZES -Mestrado - IFRJ - 2018

Centro de Referência para as Energias Solar e Eólica Sérgio de S. Brito - CRESESB. Quais são os componentes de um aerogerador? Disponível em: https://bit.ly/3sq8sdU. Acesso em: 27 de março de 2021.

Empresa de Pesquisa Energética - EPE. Balanço Energético Nacional 2020: Ano Base 2019. Rio de Janeiro: EPE, 2020.

Empresa de Pesquisa Energética - EPE. Desafios da transmissão no longo prazo - Documento de apoio ao PNE 2050. Rio de Janeiro: EPE, 2018.

Global Wind Energy Council - GWEC. GWEC: North and Latin America increased wind power installations by $\mathbf{6 2 \%}$ in $\mathbf{2 0 2 0}$. Disponível em: https://gwec.net/north-and-latin-america-increasedwind-power-installations-by-62-in-2020/. Acesso em: 23 de março de 2021.

HANSEN, Anca D. Generators and power electronics for wind turbines. In: ACKERMANN, T. Wind Power in Power Systems, Second Edition. United Kingdom: John Wiley \& Sons Ltd., 2012.

Ministério das Minas e Energia - MME. Portaria nº 444, de 25 de agosto de 2016. Disponível em: http://www2.aneel.gov.br/cedoc/prt2016444mme.pdf. Acesso em: 27 de março de 2021.

Operador Nacional do Sistema - ONS. O Sistema em números. Disponível em: www.ons.org.br/paginas/sobre-o-sin/o-sistema-em-numeros. Acesso em: 19 de março de 2021. PINTO, Milton de O. Fundamentos de energia eólica. Rio de Janeiro: LTC. 2018.

Revista 0 Setor Elétrico. Plantas eólicas. Disponível em: https://www.osetoreletrico.com.br/plantas-eolicas/. Acesso em: 27 de março de 2021. TOLMASQUIM, Mauricio T. Energia renovável: hidráulica, biomassa, eólica, solar, oceânica. Rio de Janeiro: EPE, 2016.

WEG. Ventos do sudeste ganham nova rota. Disponível em: https://www.weg.net/institutional/BR/pt/news/produtos-e-solucoes/ventos-do-sudeste-ganhamnova-rota. Acesso em: 27 de março de 2021. 